\title{
Effect of total solids contents on the performance of anaerobic digester treating food waste and kinetics evaluation
}

\author{
Xiao-fei Zhao ${ }^{1}$, Yan-qi Yuan ${ }^{1}$, Qing-kong Chen ${ }^{1}, \mathrm{Qi} \mathrm{Li}^{1}$, Yan $\mathrm{Huang}^{3}$, Di $\mathrm{Wu}^{2}$, and $\mathrm{Lei}^{2}{ }^{2}{ }^{*}$ \\ ${ }^{1}$ Engineering Laboratory of Environmental \& Hydraulic Engineering, Chongqing Jiaotong University, Chongqing 400074, China \\ ${ }^{2}$ Key Laboratory of Three Gorges Reservoir Region's Eco-Environment, Ministry of Education, Chongqing University, Chongqing \\ 400045, China \\ ${ }^{3}$ College of Food Science Southwest University, Southwest University, Chongqing 400715, China
}

\begin{abstract}
The effects of total solids (TS) content on the performance of anaerobic digestion (AD) treating food waste $(\mathrm{FW})$ and kinetic characteristics were investigated in mesophilic batch reactors. The results showed that FW could be digested normally in the AD system within the TS of $3 \%-30 \%$. The volume methane yield of dry-AD increased by 5.2-10.6 times than that of wet-AD and the degradation time of unit substrate was shortened by $35 \%-71 \%$. The system stability indicators of dry-AD, such as $\mathrm{pH}, \mathrm{VFA} / \mathrm{TA}$, TAN and salt remain within the suppression threshold after digestion. dry-AD had obvious advantages. The kinetic analysis showed that ADM1 could be used to simulate the anaerobic digestion reactor of FW, and accurately simulated the methane production in different TS systems after calibrating. With the increase of TS, the hydrolysis and methane production showed a tendency to increase first and then decrease, but the decrease rate of hydrolysis was higher than that of methanogene. Increasing TS simultaneously weaken the hydrolysis rate and methanation rate, but the effect on the hydrolysis and acidification phase weaker. The ratio of the hydrolysis rate constant to the methanogenic Monod maximum specific absorption rate (khy/km_ac) was a new perspective to used to evaluate the balance between the hydrolysis stage and the methane production stage. The results show that the khy/km_ac ratio of the $15 \%$ TS and $20 \%$ TS experimental groups was close to 1 . It can be speculated that the system TS between $15 \%-20 \%$ can be used as recommended value in anaerobic digestion engineering design to treat FW. Within this TS range, hydrolysis and methane production dynamics matching, the accumulation of inhibitors is also in a relatively moderate state in the threshold.
\end{abstract}

\section{Introduction}

Food waste (FW), usually from residential, commercial establishments, institutional and industrial sources, is generated at an ever-increasing rate which causing "waste oil", "'garbage pig'" and some other problems of food safety [1]. Therefore, the appropriate treatment methods were required. Nowadays the FW disposal methods mainly include landfill, animal feed, aerobic composting and anaerobic digestion (AD), etc. AD technology was considered to have many advantages among all the approaches, which could not only decrease the quantity of FW but also produce clean biogas [2].

TS content is one of the major factors that can affect $\mathrm{AD}$ process stability and the subsequent bioenergy production from the substrate [3.4]. It affects the degradation rate of substrate, growth of bacteria, and treatment efficiency of reactor, specifically. $\mathrm{AD}$ processes can be classified according to their TS content into Wet-AD (TS content less than 15\%) or Dry-AD (TS content equal to or higher than 15\%) [5]. Dry-AD has been claimed to be advantageous over Wet-AD for a number of reasons including smaller reactor volume, lower energy requirements for heating, minimal material handling, and lower total parasitic energy loss [6]. Liao et al. found the volumetric biogas production rate and the treatment capability of digesters for sludge increased significantly [7]. Duan et al. also pointed out dry-AD of sewage sludge can withstand the organic load rate (OLR) higher than the wet system 4 to 6 times [8]. It shows that dry-AD has great potential for development. However, at present, the anaerobic digestion system for FW using industrial scale mostly adopts the wet process, and the dry process is less used [9]. In laboratory studies, many researchers have explored the anaerobic digestibility of food wastes in systems with different TS contents, but these studies often involve digestion with multiple substrates or only within a narrow TS threshold [10.11]. Although $\mathrm{Yi}$ et al. controlled the substrate TS of 5\% to $20 \%$ in the semi-continuous food waste anaerobic digestion reactor, the TS of the entire system was only $4.1 \%$ after mixing with the inoculated sludge, which was still wet anaerobic digestion [1]. There was little literature on the performance of $\mathrm{FW}$ anaerobic digestion system when TS was greater than $15 \%$.

\footnotetext{
* Corresponding author: lileicqu@126.com
} 
Mathematical models are an important tool in many fields of research, and mathematical models can simulate and represent major aspects of biological systems, allowing certain hypotheses to be developed and validated to improve understanding of the system [12]. At present, the dynamic models widely used were firstorder model and Gompertze model [13]. Both models can only express hydrolytic or methanogenic activity singly, with structural defects in expressing both systematic hydrolytic and methanogenic activities. Based on the four-stage anaerobic digestion theory, ADM1 model includes 19 chemical processes and 2 physicochemical processes. Simulating the whole process of organic degradation and the behaviour of various compounds in the reactor, the ADM1 model is a classic model in the field of anaerobic digestion [14]. Originally ADM1 designed for $\mathrm{AD}$ of wastewater and less used in anaerobic digestion systems for food waste commonly [15]. The application of characterization of kinetic characteristics of FW anaerobic digestion system under different TS has not been reported yet.

For these reasons, this study intends to explore the performance of FW anaerobic digestion system with larger TS (3\%-30\%). The performance of the reactor was comprehensively evaluated from the aspects of gas production performance, organic removal efficiency and reactor stability. In the meantime, the effect of TS on gas production performance and its kinetic mechanism are studied from the perspective of gas production kinetics using the ADM1 model.

\section{Materials and methods}

\subsection{Substrates and inoculums}

FW collected from a school canteen was used as the substrate. As soon as the samples were collected, coarse impurities such as bones and plastics were removed and placed in boiling water for the removal of the surface floating oil. Then it was subject to solid-liquid separation through a sieve with $2 \times 2 \mathrm{~mm}$ lattice, and the obtained solid part was shredded into particles by a Robot-Coupe Shredder. At last, the materials packed into $4 \mathrm{~L}$ plastic storage bags, and pryopreserved at $-20{ }^{\circ} \mathrm{C}$. One day prior to use, the frozen feedstock was thawed, and stored at $4{ }^{\circ} \mathrm{C}$.

The inoculum used in batch experiments was the anaerobic digested sludge discharged from a laboratoryscale anaerobic digester which operated for more than three months normally. The digester was a $30 \mathrm{~L}$ tank fed with $\mathrm{FW}$ at a temperature of $37 \pm 1{ }^{\circ} \mathrm{C}$, TS content of $12.17 \%$ and OLR of $3 \mathrm{~g} \mathrm{VS} / \mathrm{L}$. Before inoculation, take a specific amount of sludge in a thermostatic water bath at $37 \pm 1{ }^{\circ} \mathrm{C}$ for pre-incubation. When gas production was almost zero for three consecutive days, it was assumed that the background substrate in the sludge was completely consumed and then applied to the experiment. The characteristics of feed substrates and inoculum were shown in Table 1.
Table 1. Characteristics of feed substrates and inoculum.

\begin{tabular}{|c|c|c|c|}
\hline Parameters & Units & Substrate & Inoculum \\
\hline $\begin{array}{l}\text { Total solids } \\
\text { (TS) }\end{array}$ & $\begin{array}{l}\% \text { of wet } \\
\text { weight }\end{array}$ & $25.35 \pm 0.31$ & $12.17 \pm 0.21$ \\
\hline $\begin{array}{c}\text { Volatile solids } \\
\text { (VS) }\end{array}$ & $\begin{array}{c}\% \text { of wet } \\
\text { weight }\end{array}$ & $24.17 \pm 0.52$ & $6.78 \pm 0.13$ \\
\hline $\mathrm{VS} / \mathrm{TS}$ & - & $0.95 \pm 0.06$ & $0.56 \pm 0.22$ \\
\hline $\mathrm{pH}$ & - & $5.88 \pm 0.12$ & $7.44 \pm 0.15$ \\
\hline Carbohydrates & $\%$ of VS & $49.86 \pm 2.17$ & \\
\hline Protein & $\%$ of VS & $39.31 \pm 0.11$ & - \\
\hline Lipids & $\%$ of VS & $10.83 \pm 0.59$ & - \\
\hline $\mathrm{C}(\%)$ & $\%$ of TS & $51.78 \pm 0.22$ & - \\
\hline $\mathrm{H}(\%)$ & $\%$ of TS & $5.71 \pm 0.23$ & - \\
\hline $\mathrm{O}(\%)$ & $\%$ of TS & $34.32 \pm 0.24$ & - \\
\hline $\mathrm{N}(\%)$ & $\%$ of TS & $3.19 \pm 0.27$ & - \\
\hline $\mathrm{C} / \mathrm{N}$ & - & $16.23 \pm 1.26$ & - \\
\hline $\begin{array}{l}\text { Theory methane } \\
\text { yield (TMY) }\end{array}$ & $\begin{array}{c}\mathrm{mL} \mathrm{CH}_{4} /(\mathrm{g} \\
\mathrm{VS})\end{array}$ & $\begin{array}{c}527.23 \pm 6.3 \\
3 \\
\end{array}$ & - \\
\hline
\end{tabular}

\subsection{Batch experiments setup}

Batch AD experiments were carried out in $500 \mathrm{~mL}$ (effective volume $300 \mathrm{~mL}$ ) serum bottle. By controlling the total effective volume and substrate-inoculum ratio ( $\mathrm{S} / \mathrm{I}$, based on VS) a constant, the substrate, inoculum, and water content at a particular TS level were calculated. In present study, S/I was set at 0.5 according to the proportion of substrate and inoculum in the mixture. The TS level was set by adding water or centrifuging to adjust the system TS concentration. Seven different TS contents were tested to represent "wet" to "dry" anaerobic digestion system: G3(3\%), G5(5\%), G8(8\%), G15(15\%), G20(20\%), G25(25\%) and G30(30\%), respectively. Each group was set to three parallel. After the mixture was added into the bottle, the serum bottle were flushed with $\mathrm{N}_{2}$ three minutes to remove $\mathrm{O}_{2}$ and then sealed with rubber plugs. The serum bottle were placed in a water bath without stirring and keep the reaction temperature at $37 \pm 1{ }^{\circ} \mathrm{C}$.

\subsection{ADM1 Modeling}

ADM1 standard model structure which published by the International Water Association (IWA) in 2002 was used in this study [14]. The unit of model unified use $\mathrm{kg}$ $\mathrm{COD} / \mathrm{m}^{3}$. According to the results of elemental analysis, the conversion relationship between $\mathrm{VS}$ and COD is calculated by stoichiometry, and the conversion coefficient is $1.51 \mathrm{~g} \mathrm{COD} / \mathrm{g} \mathrm{VS}$. The methane volume and COD conversion factor under the indicator mode were $2.85 \mathrm{~kg} \mathrm{COD} / \mathrm{m}^{3} \mathrm{CH}_{4}$ [16]. Thus, the gas production data of unit VS can be converted into gas production data of unit COD and the model substrate input $\mathrm{Xc}$ is $1 \mathrm{~kg} \mathrm{COD} / \mathrm{m}^{3}$. The stoichiometric parameters were calculated using the formula (equal 1-3) proposed by Koch et al. [17].

$$
\begin{aligned}
f_{c h_{-} X c} & =\frac{C H}{V S} \times 100 \% \\
f_{p r_{-} X c} & =\frac{P R}{V S} \times 100 \%
\end{aligned}
$$




$$
f_{l i \_} X c=\frac{L I}{V S} \times 100 \%
$$

Where $\mathrm{CH}$ is the carbohydrate content of the substrate $(\mathrm{g})$; PR is the protein content of the substrate (g); LI is the lipid content of the substrate (g); Soluble inert ingredients and granular inert ingredients are not considered, because the substrate input to the organic component COD, the main stoichiometric parameters in Table 2. The kinetic parameters except the carbohydrates hydrolysis rate constant khy_ch, protein hydrolysis rate constant khy_pr, lipid hydrolysis rate constant khy_li and methanogenic Monod maximum specific absorption rate $\mathrm{km} \_\mathrm{ac}$, the other parameters using Bastone et al proposed the recommended value (medium temperature solid) [14]. The model was implemented using the AQUASIM 2.0 modeling platform [18].

Table 2. The input value of the stoichiometric coefficients in ADM1.

\begin{tabular}{|c|c|c|c|}
\hline parameter & Description & Unit & Value \\
\hline fch_Xc & $\begin{array}{c}\text { Carbohydrates in } \\
\text { substrate }\end{array}$ & $\mathrm{kgCOD} / \mathrm{kgCOD}$ & 0.50 \\
\hline fpr_Xc & The protein in substrate & $\mathrm{kgCOD} / \mathrm{kgCOD}$ & 0.40 \\
\hline fli_Xc & Lipids in substrate & $\mathrm{kgCOD} / \mathrm{kgCOD}$ & 0.10 \\
\hline fsI,Xc & $\begin{array}{c}\text { Soluble inert ingredients } \\
\text { in substrate }\end{array}$ & $\mathrm{kgCOD} / \mathrm{kgCOD}$ & 0 \\
\hline fxI,Xc & $\begin{array}{c}\text { Particulate inert } \\
\text { ingredients in substrate }\end{array}$ & $\mathrm{kgCOD} / \mathrm{kgCOD}$ & 0 \\
\hline
\end{tabular}

\subsection{Analysis methods}

TS and volatile solids (VS) were measured according to standard methods [19]. The $\mathrm{pH}$ was measured using a $\mathrm{pH}$ meter (Shanghai lei ci, PHS-3E). Elemental compositions $(\mathrm{C}, \mathrm{H}, \mathrm{O}, \mathrm{N})$ of substrates were measured by an elemental analyzer (Vario EL cube, Germany). Protein and lipids was determined according to Li et al. [20]. Carbohydrates content was calculated by subtracting the content of protein and lipids from VS content (equal 4).

$$
C H(\%, V S)=1-P R(\%, V S)-L I(\%, V S)
$$

Chemical oxygen demand (COD) were analyzed by using a digest instrument (DRB200, Hach, USA) for digestion of the sample and a spectrophotometer (DR1010, Hach, USA) for colorimetric determination. Volatile fatty acid (VFA) were determined with the gas chromatography(Agilent, USA). Total ammonia nitrogen (TAN) was analyzed using a DR-2800 spectrophotometer (HACH, USA). Salt was measured according to Montgomery et al. [21]. Total alkalinity (TA) were determined through a two-step titration method [11].

The volume of methane production was determined by displacing $3 \mathrm{~mol} / \mathrm{L}$ solution of sodium hydroxide, and the measured methane volume was adjusted to the volumes at standard temperature $(273.15 \mathrm{~K})$ and pressure $(101.325 \mathrm{kPa})$ [7]. In order to avoid that the volume of the dry group sample's supernatant is too little after centrifugation, $\mathrm{pH}, \mathrm{VFA}, \mathrm{TA}$ and TAN concentrations were determined by mixing the sample with deionized water (1:5) for $15 \mathrm{~min}$ and then testing the supernatant for dry digestion samples [11.22].
The organic degradation was represented by the reduction rate of VS (VSr, \%). It can be calculated by the equal 5 [23], assuming that the mass of inorganic fraction is constant during $\mathrm{AD}$.

$$
V S_{\mathrm{r}}=\frac{\mathrm{vs}_{0}-\mathrm{vs}_{t}}{\mathrm{vs}_{0} \times\left(1-\mathrm{vs}_{t}\right)}
$$

where VSt is the VS of the digestate at a certain time during $\mathrm{AD}, \mathrm{g} / \mathrm{g}$ TS or $\%$; $\mathrm{VS}_{0}$ is the VS of the initial mixture, $\mathrm{g} / \mathrm{g}$ TS or $\%$.All these tests were conducted in duplicate for a sample, and the data had shown that were the averages based on three parallel experiments in this paper.

\section{Results and discussion}

\subsection{Digester performance during wet to dry AD}

\subsection{1 methane production}

The (a) methane production rate, (b) daily methane production, (c) volumetric methane production and (d) volumetric methane production rate at different TS control level is shown in Fig. 1.

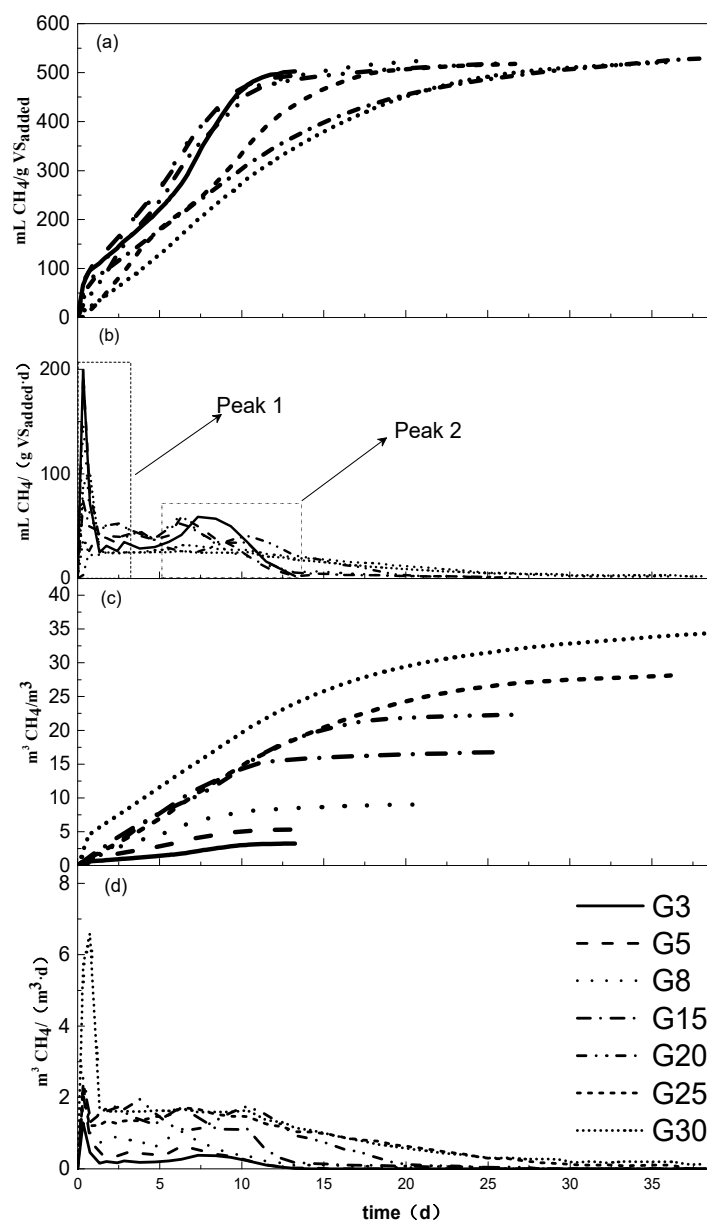

Fig 1. The (a) specific methane yield (b) daily methane production, (c) volumetric methane production and (d) volumetric methane production rate at different TS control level. 
According to Fig. 1, there was no significant difference in cumulative methane production rate ( $\mathrm{P}>0.05)$. All groups obtained approximately 95.3\%, $94.3 \%, 99.3 \%, 98.4 \%, 98.4 \%, 99.0 \%$ and $100 \%$ of TMY after digestion, respectively, for the digestion system with the TS content of $3 \%, 5 \%, 8 \%, 15 \%, 20 \%, 25 \%$, and $30 \%$. The maximum TS content of $30 \%$ has exceeded the TS values previous mentioned by Poirier et.al and Nguyen et.al which proposed to be $10 \%$ and $20 \%$. This indicated that the AD system with TS contents ranging from $3 \%$ to $30 \%$ could be digested successfully. Moreover, The cumulative methane production in this study did not decrease with the increase of TS, but was closer to the TMY. It was in contrast to studies by Liao et al. [7] in the low TS range (1.79\%-15.67\%) and Abbassi-Guendouz et al. [24] in the high TS range (10\%-35\%) which found that with the increase of TS, the cumulative methane production would be significantly decreased. Liu et al. found the highest cumulative biogas yield was obtained when FW accounted for $100 \%$ in high solid co-digestion system with sludge [25]. They deduced that the addition of FW altered the sticky status of sludge cake and improved mass transfer in high-solids sludge [25]. This may be the reason why this study can still maintain good gas production performance under high TS level.

As shown in Fig. 1b, generally, the daily methane yield of all groups showed a downward trend despite the partial fluctuations. In terms of the daily methane production, the wet groups (G3-G8) and the dry groups (G15-G30) showed a large difference. The dry groups was maintained at a stable level of gas production and did not exhibit significant fluctuations. However, the wet groups showed large fluctuations of gas production in the initial stage and after adapting to the environment. In overall, there were two peak in wet groups. The first peak appears on the first day, and the second peak appears gradually in 6 to 10 days. This phenomenon was also mentioned in previous study [11.26]. At the beginning of the reaction, there is a certain amount of dissolved organic matter and background TA in the reactor, which can provide sufficient substrate for the microorganism and suitable gas production environment. At this time, the first peak occurs in the gas generation, and then the substrate was hydrolyzed rapidly. A large amount of VFA causes a drop in $\mathrm{pH}$, which in turn inhibits the activity of methanogenic microorganisms and decreases the rate of gas production. Until the organic matter content of the system is gradually decreased, the substrate limit causes the rate of acid production to decrease, the inhibition to the methane production stage to weaken, and the rate of gas production to gradually rise, showing a second peak of gas production. The gas production curve of the wet system showed two peaks. The reason was that the internal mass transfer of the biogas slurry of the wet system was fast. After the rapid gas production and acid production in the early stage, the methane production process was inhibited by the intermediate product VFA. Compared with the wet system, the internal mass transfer of the biogas slurry of the dry system was slower, which would cause 1) the early gas production process was slow and the gas production curve did not have a peak; 2) the intermediate product VFA was not significantly inhibited in the later stage. Even if acidification occurred, it was local rather than global. Therefore, it was reasonable to point out that dry systems were more resistant to disturbances [24]. Dry system have great advantages in volumetric methane production. As shown in Fig. 1c, the volumetric methane production increased sharply with the increase of TS. Compared with G3, the volumetric methane production of G15, G20, G25 and G30 increased 5.2, 6.9, 8.7 and 10.6 times respectively after digestion. Even in the same time period as the G3 digestion, the volumetric methane production in the dry groups(G15-G30) was still 4.8 to 7.4 times that of the G3 group (Fig. 1c).

\subsubsection{Digester efficiency}

In addition to the production of clean energy in the form of biogas, another purpose of anaerobic digestion of FW is to remove organic. In this study, the substrate concentration (SC), CODr and degradation time based on per substrate (DT) were used to evaluate the digester efficiency. The average performance of different group was shown in Table 3.

Table 3. Average performance of all groups.

\begin{tabular}{|c|c|c|c|c|c|c|c|}
\hline & G3 & G5 & G8 & G15 & G20 & G25 & G30 \\
\hline SC (g VS/L) & 6.5 & 10.7 & 17.2 & 32.3 & 43.1 & 53.9 & 64.8 \\
\hline Degradation time (d/(g VS) & 2.05 & 1.33 & 1.24 & 0.8 & 0.63 & 0.67 & 0.59 \\
\hline CODr(\%) & $0.91 \pm 0.01$ & $0.92 \pm 0.02$ & $0.91 \pm 0.01$ & $0.9 \pm 0.03$ & $0.90 \pm 0.01$ & $0.90 \pm 0.02$ & $0.84 \pm 0.03$ \\
\hline
\end{tabular}

By setting different initial SC, the S/I and effective volume of each group were controlled to a certain value. All groups of anaerobic digestion were able to produce methane normally until the end of the reaction. It was consistent with the previous proposed that Dry-AD could withstand 4 to 6 times SC than Wet-AD [8]. In batch experiments, the ability to withstand such a SC threshold from 6.5 to $64.8 \mathrm{~g} \mathrm{VS} / \mathrm{L}$ and running well which was also mentioned in previous studies [7.11]. In the same volume, dry-AD can treat more food waste, and the energy consumption per unit substrate treating also decreases.

Besides SC, the degradation and removal of substrates is a parameter that further evaluates the efficiency of the reactor. The COD removal rate of each group is shown in Table 3. Although the G30 declined slightly, the overall trend was not significant $(p>0.5)$. This indicates that the FW could all normally degrade and produce biogas in both the wet and dry groups, with 
very little conversion to intermediate products after digestion. This is consistent with the fact that there is no decrease in gas production in dry groups. Dry group not only able to withstand higher SC and maintain a high CODr, the degradation time per gram of added VS (T) obvious advantages. The DT of the G3, G5, G8, G15, G20, G25 and G30 groups were 2.05, 1.33, 1.24, 0.8, $0.63,0.67$ and $0.59 \mathrm{~d} /(\mathrm{g}$ VS), respectively. It can be seen from the G15 and G8 that the DT reduced by 35\% at least. Similarly, G30 than G3 reduced by $71 \%$. To sum up, the DT of dry groups than wet groups reduced by about $35 \%-71 \%$.

\subsubsection{Process stability}

The stability and inhibition of different TS content were analyzed by monitoring the variations of process parameters. Table 4 summarizes the values of the main parameters indicating system stability $(\mathrm{pH}, \mathrm{VFA}, \mathrm{TA})$ and potential inhibitory chemicals (TAN and $\mathrm{Na}^{+}$) at different TS contents.

Table 4. Summary of performance parameters on system stability and inhibition in different groups.

\begin{tabular}{|c|c|c|c|c|c|c|}
\hline group & Finial pH & $\begin{array}{c}\text { Finial VFA } \\
(\mathrm{mg} / \mathrm{L})\end{array}$ & $\begin{array}{c}\text { Finial TAN } \\
(\mathrm{mg} / \mathrm{L})\end{array}$ & $\begin{array}{c}\text { Finial salt } \\
(\mathrm{mg} / \mathrm{L})\end{array}$ & $\begin{array}{c}\text { Finial TA } \\
\left(\mathrm{mg} \mathrm{CaCO}_{3} / \mathrm{L}\right)\end{array}$ & VFA/TA \\
\hline G3 & $7.41 \pm 0.01$ & $61.68 \pm 15.60$ & $424.17 \pm 22.55$ & $670.56 \pm 34.16$ & $1698.67 \pm 42.47$ & $0.04 \pm 0.01$ \\
\hline G5 & $7.47 \pm 0.02$ & $99.38 \pm 31.28$ & $766.67 \pm 101.56$ & $1143.89 \pm 68.32$ & $2746.18 \pm 318.03$ & $0.04 \pm 0.02$ \\
\hline G8 & $7.5 \pm 0.03$ & $100.86 \pm 17.64$ & $799.34 \pm 72.96$ & $3550.00 \pm 71.00$ & $3425.64 \pm 149.14$ & $0.03 \pm 0.01$ \\
\hline G15 & $7.68 \pm 0.02$ & $512.31 \pm 36.85$ & $933.17 \pm 151.12$ & $4603.00 \pm 631.06$ & $8139.44 \pm 49.04$ & $0.06 \pm 0.00$ \\
\hline G20 & $7.73 \pm 0.02$ & $465.40 \pm 28.12$ & $1070.22 \pm 48.82$ & $3461.25 \pm 319.99$ & $9441.33 \pm 280.01$ & $0.05 \pm 0.00$ \\
\hline G25 & $7.87 \pm 0.01$ & $1190.43 \pm 335.90$ & $1135.23 \pm 71.73$ & $4391.70 \pm 465.49$ & $10089.23 \pm 1491.73$ & $0.12 \pm 0.04$ \\
\hline G30 & $7.99 \pm 0.02$ & $790.08 \pm 65.33$ & $1395.22 \pm 150.95$ & $5207.60 \pm 101.68$ & $7794.63 \pm 59.99$ & $0.1 \pm 0.01$ \\
\hline
\end{tabular}

is more prone to inhibition than wet groups. In

The accumulation of VFA can cause disturbance to the AD system. If the concentration of VFA is too high, the buffer capacity will be reduced and the $\mathrm{pH}$ will drop sharply [27]. In this study, VFA and $\mathrm{pH}$ were 424.17$1533.17 \mathrm{mg} / \mathrm{L}$ and 7.40-7.99 after digestion in each group, respectively. The VFA value is less than its inhibitory threshold of $3000 \mathrm{mg} / \mathrm{L}$ and the $\mathrm{pH}$ is within the optimum range [28]. TA and VFA/TA are effective parameters for evaluating the stability of the reactor [26]. After normal digestion, the TA of the dry groups was significantly higher than that of the wet groups which indicated that the dry system has a large buffering capacity. The researchers pointed out that the VFA/TA of the system should be below 0.35 in the continuous anaerobic digestion system [26]. The lower VFA/TA indicates the system load is too low, while more than 0.6 prone to system instability [11]. Although this study is a batch experiment, the index can also provide some reference value. From Table 4, the final VFA/TA of different TS groups slowly increased from 0.04 to 0.12 , maintained at a low level. It indicates that the reactor was operating stably. Even, indicating that the system might still be able to withstand higher SC. In the AD process, it is generally considered that the inhibition threshold of TAN concentration is $1700-14000 \mathrm{mg} / \mathrm{L}$. As shown in Table 4, TAN concentrations in the dry groups (G15-G30) ranged from $933 \mathrm{mg} / \mathrm{L}$ to $1600 \mathrm{mg} / \mathrm{L}$, both below the inhibitory threshold. But the G30 was 3.3 times higher than that of the G3. This is because the SC of the G30 was much higher than that of the G3, and more substrates were degraded to produce more ammonia nitrogen. On the other hand, the moisture content of G30 is much smaller than the G3, with less water available for dilution of ammonia nitrogen. Salt also has a similar situation. Although all groups had a salt concentration below $5500 \mathrm{mg} / \mathrm{L}$, salt concentrations in the high TS groups were higher. Therefore, dry groups engineering applications, taking into account the digestive juice reflux, it will appear the same trend. This is consistent with the observations of the rest of the researchers [7.11].

In short, Dry-AD was able to withstand higher SC and obtain larger volumetric methane yields than WetAD in this study. System stability indicators, such as $\mathrm{pH}$, VFA/TA, TAN and salt were also within the inhibition threshold and the stability of reactor was well. However, the risk of accumulation of inhibitors, which in turn leads to process instability, is greater in continuous batch running in dry groups.

\section{2 kinetic analysis}

\subsubsection{ADM1 simulation of methane production for FW}

ADM1 was initially proposed for sewage and sludge anaerobic digestion systems [29]. Researchers used the IWA's parameter recommendation values to simulate in the corresponding wet anaerobic digestion system and the $\mathrm{R}^{2}$ of methane generation was over $98 \%[18,30]$. In this study, the gas production results of each group were simulated with the recommended values. The $R^{2}$ of $G 3$, G5, G8, G15, G20, G25 and G30 were 91.69\%, 93.98\%, $95.32 \%, \quad 93.60 \%, \quad 75.53 \%, \quad 55.61 \%$ and $59.67 \%$, respectively. It can be seen that the $\mathrm{R}^{2}$ of sludge system and FW system are more than $90 \%$ in the similar wet system. This indicates that ADM1 is suitable for the AD of FW. Nevertheless, $\mathrm{R}^{2}$ of the FW system is much lower than that of the sludge system, which may be caused by the different substrate properties. Other researchers have encountered a similar situation when using the ADM1 model in anaerobic digestion systems such as sludge, cow dung, and bran chaff. At this point, 
some parameters of the model should be calibrated. Previous researchers modified khy and $\mathrm{km}$ ac more frequently when calibrating model parameters, which characterize the hydrolysis rate of the substrate and the acetate-type methanogenic activity, respectively [31-32]. Preliminary studies have found that, in the absence of significant suppression of the system, methanogenic acetic acid type as the dominant bacteria [33]. Hydrogen-producing methane bacteria less affected. Therefore, the present study aims to calibrate the model by modifying the model parameters khy, which characterize the hydrolysis rate, and $\mathrm{km}$ ac, which characterizes the activity of acetic acid-producing methanogens. The model parameters that characterize the Hydrogenotrophic methanogens activity apply the recommended values directly. Similar assumptions are also mentioned in the study by Razaviarani et al. [31].

Whereas early ADM1 was proposed in wet systems [14], the TS of a typical wet AD process in the current industrial scale is around 5\%. Therefore, G5 gas production data for calibration and the calibration results shown in Fig. 2.

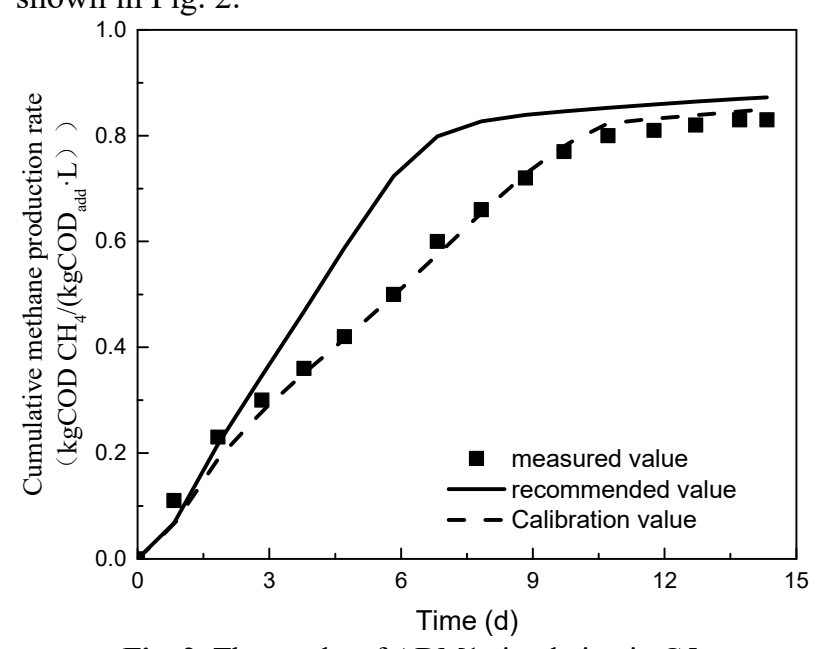

Fig. 2. The results of ADM1 simulation in G5.

It can be seen from the Fig. 2 that the simulation result of G5 is basically the same as the experimental one after modifying khy_ch, khy_pr, khy_li and km, ac values, and the goodness of fit $\mathrm{R}^{2}$ reaches $99.08 \%$. Using the calibrated parameter values to simulate the remaining wet groups, $\mathrm{R}^{2}$ of G3 and G8 were $99.13 \%$ and $99.05 \%$, respectively. The $\mathrm{R}^{2}$ was found to have a slight decrease when the G5 calibrated parameter values applied to G3 and G8, but also to better simulate the experimental results. This showed that the calibrated ADM1 model can be used to accurately simulate the methane production performance of a wet AD of FW system.

\subsubsection{Effect of TS on methane production dynamics}

When the calibrated ADM1 model was used for dry groups simulations, the $\mathrm{R}^{2}$ decreased again below $65 \%$ (62.31\%, 60.12\%, 55.25\%, 48.77\%, respectively). This may be due to TS has a great impact on the kinetics of $\mathrm{AD}$ process. It is not possible to obtain a good effect by using the previous modified parameters for gas production simulation. Using the integrated parameter estimation function of AQUASIM 2.0 software, it is necessary to study the changes of khy_ch, khy_pr, khy_li and $\mathrm{km}$, ac which characterize the hydrolysis rate and methanogenic rate under different TS (Table 5). As can be seen from Table 5, after further modified khy ch, khy pr, khy li and km ac under different TS, the $\mathrm{R}^{2}$ of each group was over $99 \%$ which indicating that the methane yield simulated by the ADM1 model at this time basically agrees with the actual operation. This good fitting result is due to the fact that the ADM1 model is a structured model that describes the changes of various state variables at different stages of the $\mathrm{AD}$ process[18.34].

Further analysis of the modified model parameters showed that with the increase of TS, khy_ch increased first and then decreased. G15 group reached the maximum value. khy pr and khy li showed a monotonous decreasing trend. This indicates that the higher the TS, the slower the rate of protein and lipid hydrolysis, while carbohydrate hydrolysis rate increases in the wet TS range and drastically decreases in the dry TS range. Since anaerobic digestion is an in-line, ordered biochemical process as a whole, the effect of the parallel hydrolysis of carbohydrates, proteins and fats on the whole process should be more towards its mean rather than overlying. Therefore, Fig. 3 characterizes the overall hydrolysis rate constant with the mean of the three classes of material hydrolysis rates. As can be seen from Fig. 3, the total hydrolysis rate constant khy of the wet groups is at a high level. With the increase of TS, the khy value increases gradually and then decreases rapidly. Previous studies have found that there was a marked reduction of hydrolysis rate at TS of $15 \%$ [24]. This range is exactly the critical TS value for both wet and dry conditions.

Similar to khy, km_ac also shows a trend of first increasing and then decreasing. The difference was that $\mathrm{km} \_\mathrm{ac}$ decreases less. This indicates that the limitation of the high TS system on the methanogenic stage was lower than the limit on the hydrolyzed stage. Significant analysis showed that khy_ch, khy_pr and khy_li were significantly different between the wet groups and the dry groups $(p<0.05)$, while the difference of $k m \_a c$ was not significant $(\mathrm{p}>0.05)$.

Since both khy and km_ac tend to non-monotonic with the increase of TS, the stability of the system can not be directly judged from the change of khy and $\mathrm{km}$ ac. However, the reason why the $\mathrm{AD}$ reactor is unstable does not depend on the absolute rate at a certain stage. It is often because of metabolic imbalances between hydrolytic and methanogenic phases. Therefore, the relative trend of the two phases is an important factor in determining its stability. In view of this, after analyzing the trend of the two kinetic parameters separately, this study further considered the relationship between the two kinetic parameters and the process stability. As can be seen from Fig. 3, khy $/ \mathrm{km}$ ac tends to decrease monotonously with the increase of TS. 
Table 5. The fitting results of ADM1 model.

\begin{tabular}{|c|c|c|c|c|c|c|c|c|c|c|}
\hline model & parameter & unit & $\begin{array}{c}\text { Default } \\
\text { value }\end{array}$ & G3 & G5 & G8 & G15 & G20 & G25 & G30 \\
\hline \multirow{7}{*}{ ADM1 } & khy_ch & $1 / \mathrm{d}$ & 10 & 10.11 & 15.79 & 17.43 & 18.03 & 8.10 & 5.24 & 4.98 \\
\hline & khy_pr & $1 / \mathrm{d}$ & 10 & 19.98 & 17.00 & 13.71 & 0.13 & 0.12 & 0.08 & 0.08 \\
\hline & khy_li & $1 / \mathrm{d}$ & 10 & 13.02 & 11.50 & 10.39 & 9.99 & 8.51 & 0.07 & 0.07 \\
\hline & khy & $1 / \mathrm{d}$ & - & 14.37 & 14.76 & 13.84 & 9.38 & 5.58 & 1.80 & 1.71 \\
\hline & $\mathrm{k}_{\mathrm{m}, \mathrm{ac}}$ & $\mathrm{kgCOD}_{\mathrm{sub}} /\left(\mathrm{kgCOD}_{\mathrm{m}} \cdot \mathrm{d}\right)$ & 8 & 4.30 & 4.84 & 5.00 & 7.00 & 4.49 & 3.40 & 3.27 \\
\hline & khy $/ \mathrm{km}_{\text {anc }}$ & 1 & - & 3.34 & 3.05 & 2.77 & 1.34 & 1.24 & 0.53 & 0.52 \\
\hline & $\mathrm{R}^{2}$ & 1 & - & $99.30 \%$ & $99.08 \%$ & $99.20 \%$ & $99.33 \%$ & $99.72 \%$ & $99.62 \%$ & $99.35 \%$ \\
\hline
\end{tabular}

khy_ch, first-order hydrolysis rate constant of carbohydrate; khy_pr, first-order hydrolysis rate constant of protein; khy_li, first-order hydrolysis rate constant of lipid; khy, equal to the mean of khy_ch,khy_pr and khy_li; km_ac, Monod maximum specific absorption rate of acetic acid.

In physical sense, this index is the ratio of the hydrolysis rate constant to the methane production rate constant. It characterizes the ratio of hydrolysis to methanogenic rate. When 1) $\mathrm{khy} / \mathrm{km}_{-}$ac $<1$, the rate of hydrolysis is slow, and hydrolysis is the rate-limiting step of the digestion process. 2) khy $/ \mathrm{km}_{-}$ac $>1$, the methanogenic stage is the rate-limiting step in the digestion process. As the TS increases to $25 \%$ gradually, the value of $\mathrm{khy} / \mathrm{km}$ ac is closer to 1 in this study. This shows that the hydrolysis rate is faster than the methane production rate in the system which TS was less than $25 \%$ and the methane production stage was the ratelimiting step of the digestion process. In systems with TS $>25 \%$, khy $/ \mathrm{km}_{\text {ac }}<1$, indicating that the ratelimiting step of the $\mathrm{AD}$ process has shifted from the methanogenic to the hydrolytic-acidification stage in high TS systems. It can be seen that although increasing TS affects both hydrolysis and methanogenic stages, it has a greater impact on the hydrolysis and acidification stages. The khy/km_ac value of G15 and G20 are closer to 1 than other groups, which indicated that the optimum TS for $\mathrm{AD}$ of FW could be controlled at $15 \%-20 \%$. Within this TS range, the system was able to produce methane efficiently and achieve a more balanced dynamics.

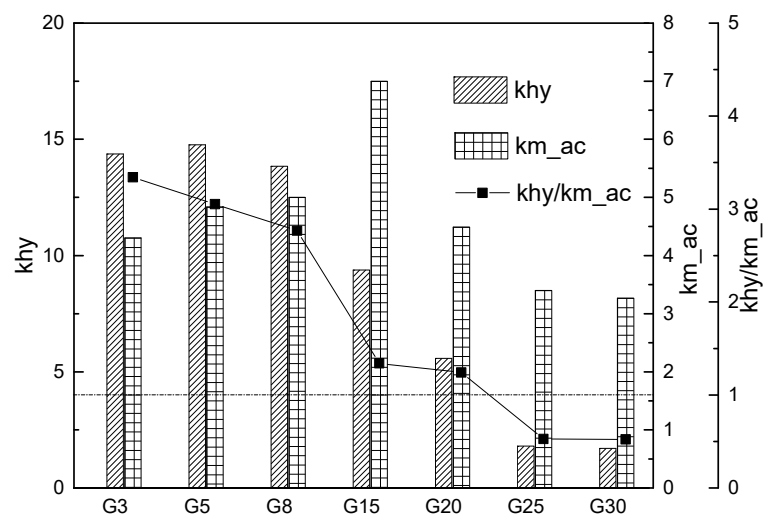

Fig. 3. Variation of kinetic parameters in different groups.

\section{Conclusion}

The AD system with TS contents ranging from 3\% to $30 \%$ could digested successfully in batch experimental. The volumetric methane production of dry groups is 5.210.6 times higher than that of wet groups. Degradation of the unit substrate, the DT of dry groups reduced by $35 \%-71 \%$ than that of the wet groups generally. Dry AD showed obvious advantages. In addition, Dry-AD was not only able to withstand higher SC and obtain larger volumetric methane yields, the system stability indicators, such as $\mathrm{pH}, \mathrm{VFA} / \mathrm{TA}, \mathrm{TAN}$ and salt were also within the inhibition threshold after digestion. The stability of reactor was well. However, it was not the higher TS, the better AD performance. Kinetic analysis showed that ADM1 used in the simulation of AD of FW, but TS has a significant effect on the kinetic parameters. With the increase of TS, the hydrolytic and methanogenic activities both increased and then decreased. It is noteworthy that hydrolysis rate declined more than methanation rate. Increasing TS both weaken the rate of hydrolysis and methanogenesis stages, but it is more damaging to the hydrolytic acidification stage. The value of khy $/ \mathrm{km}$ ac could be used to assess the match between the system hydrolysis stage and the methanogenic stage. From this new point of view, the ratio of G15 and G20 were closest to 1 in this study. It can be speculated that the system TS between $15 \%$ and $20 \%$ can be used as recommended value in anaerobic digestion engineering design to treat food waste. Within this TS range, hydrolysis and methane production dynamics matching, the accumulation of inhibitors is also in a relatively moderate state in the threshold.

This work was granted by financial support of the National Natural Science Foundation of China Youth Fund Project (51708057) and the Science and Technology Research Program of Chongqing Municipal Education Commission (Grant No.KJQN201900715).

\section{References}

1. Z. Wang, Y. Jiang, S. Wang, Y. Zhang, Y. Hu, Z. $\mathrm{Hu}, \mathrm{G}$. Wu, X. Zhan, Waste Manage., 114, 96-106 (2020)

2. J.P. Blasius, R.C. Contrera, S.I. Maintinguer, M.C.A. Alves De Castro, Biotechnology Reports, 27, e503 (2020)

3. L.S. Franca, J.P. Bassin, Biomass and Bioenergy, 143, 105866 (2020)

4. S. Riya, K. Suzuki, L. Meng, S. Zhou, A. Terada, M. Hosomi, Waste Manage., 76, 350-356 (2018) 
5. C. Rico, J.A. Montes, A. Lobo, J. Clean. Prod., 251, 119751 (2020)

6. J. Guendouz, P. Buffiere, J. Cacho, M. Carrere, J.P. Delgenes, Water Sci. Technol., 58, 1757-1763 (2008)

7. X. Liao, H. Li, Y. Cheng, N. Chen, C. Li, Environ. Technol., 35, 2652-2659 (2014)

8. N. Duan, B. Dong, B. Wu, X. Dai, Bioresource Technol., 104, 150-156 (2012)

9. Q. He, L. Li, S. Peng, X.F. Zhao, L. Qu, X.M. Wang, X.Y. Peng, China Environmental Science, 37, 10401050 (2017)

10. F.O. Agyeman, W. Tao, J. Environ. Manage., 133, 268-274 (2014)

11. X. Chen, W. Yan, K. Sheng, M. Sanati, Bioresource Technol., 154, 215-221 (2014)

12. K.R. Manchala, Y. Sun, D. Zhang, Z.W. Wang, Advances in Bioenergy, 2, 70-135 (2017)

13. L. Li, Q. He, L. Qu, D. Wu, X.M.Wang, X.Y. Peng, Journal of Environmental Sciences, 3016-3023 (2017).

14. D.J. Batstone, J. Keller, I. Angelidaki, S.V. Kalyuzhnyi, S.G. Pavlostathis, A. Rozzi, W.T. Sanders, H. Siegrist, V.A. Vavilin, Water Science \& Technology A Journal of the International Association on Water Pollution Research, 45, 65 (2002)

15. P.G. Rathnasiri, Procedia Environmental Sciences, 35, 740-748 (2016)

16. Q. Niu, T. Hojo, W. Qiao, H. Qiang, Y. Li, CHEM. ENG. J., 244, 587-596 (2014)

17. K. Koch, M. Lübken, T. Gehring, M. Wichern, H. Horn, Bioresource Technol., 101, 8158-8165,(2010)

18. J. Bai, H. Liu, B. Yin, H. Ma, X. Chen, J. Environ. Sci.-China, 52, 58-65 (2017)

19. F.W. Gilcreas, American Journal Of Public Health And The Nations Health, 56, 387 (1966)

20. Y. Li, R. Zhang, C. Chen, G. Liu, Y. He, X. Liu, Bioresource Technol., 149, 406-412 (2013)

21. H. Montgomery, J.F. Dymock, N.S. Thom, Analyst, 87, 949 (1962)

22. Y. Zhang, C.J. Banks, Waste Manage., 33, 297-307 (2013)

23. K. Koch, M. Wichern, M. Luebken, H. Horn, Bioresource Technol., 100, 5934-5940 (2009)

24. A. Abbassi-Guendouz, D. Brockmann, E. Trably, C. Dumas, J. Delgenès, J. Steyer, R. Escudié, Bioresource Technol., 111, 55-61 (2012)

25. C. Liu, H. Li, Y. Zhang, C. Liu, Bioresource Technol., 219, 252-260 (2016)

26. L. Li, Q. He, Y. Wei, Q. He, X. Peng, Bioresource Technol., 171, 491-494 (2014)

27. D. Brown, Y. Li, Bioresource Technol., 127, 275280 (2013)

28. P. Weiland, Appl. Microbiol. Biot., 85, 849 (2010)
29. D.J. Batstone, J. Keller, J.P. Steyer, Water Sci. Technol., 54, 1-10 (2006)

30. T.S.O. Souza, A. Carvajal, A. Donoso-Bravo, M. Peña, F. Fdz-Polanco, Water Res., 47, 3244-3254 (2013)

31. V. Razaviarani, I.D. Buchanan, Chem. Eng. J., 266, 91-99 (2015)

32. X. Shi, X. Yuan, Y. Wang, S. Zeng, Y. Qiu, R. Guo, L. Wang, Chem. Eng. J., 244, 258-263 (2014)

33. L. Li, Q. He, Y. Ma, X.F. Zhao, L. Qu, X.M.Wang, X.Y. Peng, China Environmental Science, 36, 33973404 (2016)

34. F. Blumensaat, J. Keller, Water Res., 39, 171-183 (2005) 